DOI: $10.14451 / 1.175 .34$

\title{
ЭКОНОМИЧЕСКИЕ СЕТИ СФЕРЫ УСЛУГ РОССИИ
}

\author{
(C) 2019 Габдрахманов Олег Фаритович \\ кандидат экономических наук, доцент кафедры экономики и финансового права \\ Институт деловой карьеры, Россия, Орехово-Зуево \\ E-mail: Gabdrahmanov@list.ru
}

\begin{abstract}
В статье рассмотрены подходы к поиску новой модели экономики, которые привели к развитию форм сетевой организации. Исследованы особенности и роль экономических сетей в сфере услуг России в контексте концепции «новой экономики». Проведен анализ подходов отечественных и зарубежных ученых к понятиям экономической сети. Рассмотрены характеристики их основных видов: экономические сети домохозяйств, экономические сети на принципах реципрокности.
\end{abstract}

Ключевые слова: сеть, «новая экономика», экономические сети, сфера услуг, классификация, организация, исследование, эффективность.

Для современного этапа развития экономики России характерны императивы, свойственные общемировым трендам в виде: динамики рыночных изменений; введения управленческих инноваций; ориентации деятельности на массовую кастомизацию; применения новейших научных достижений; использования возможностей кооперации, интеграции и сетевой организации экономической деятельности.

Подобные процессы определяют содержание теории «новой экономики» и поиск модели экономического развития, методологические аспекты которых рассмотрены в трудах отечественных и зарубежных ученых. Развитие экономических сетей в РФ находится в контексте трансформации организационно-правовых форм хозяйствующих субъектов и их интегрированных сообществ в детерминированной связи с конкурентной средой сферы услуг [1], определяющей естественный отбор и результаты функционирования.

Роль экономических сетей в новой экономике заключается в том, что они:

- служат местом приложения новых технологий и инноваций, выступающих факторами экономического роста;

- способствуют повышению скорости вводимых технологических и управленческих изменений, в том числе за счет информационных и цифровых технологий, приводя к сокращению этапов жизненного цикла товаров;

- расширяют границы экономической деятельности, обеспечивая вовлечение дополнительных ресурсов и возможностей;

- повышают роль услуг в воспроизводствен- ном процессе, изменяют модели и структуру потребления, формируют новый образ жизни у значительной части населения;

- выполняют демпфирующую функцию, снижая уровень социально-экономической напряженности в обществе, вызванного безработицей и низким уровнем жизни граждан.

В процессе исследования были использованы труды отечественных и зарубежных ученых по вопросам организации и деятельности хозяйствующих субъектов сферы услуг, вопросам интеграции, формирования и функционирования сетей.

Концептуально «новая экономика», составляющей которой является сетевая форма ее организации, в трудах ученых носит многоаспектный характер. Она выступает как ответ на глобальные сдвиги и вызовы современности [2;3], способ системной модернизации [4;5], как модель развития страны на перспективу [6;7], что требует раскрытия ее генезиса, эволюции и эффекта [8]. Зарубежные авторы исследуют причины отклонений поведения людей от традиционных моделей поведения (Талер Р. и др.) [9], причины неустойчивости кредитных сетей (Altinoglu, Levent и др.) [10].

Применительно к практическим потребностям России направления новой экономики рассмотрены в контексте преодоления кризисов и решения проблем неопределенности [11], поиска путей социально-экономического развития [12].

Экономические сети домохозяйств. Домохозяйства в современной статистике рассматриваются в виде территориально локализованной самостоятельной хозяйственной единицы, 
а также единицы статистического учета и социально-экономических исследований, представляя собой элементарный микроколлектив, обладающий определенными характеристиками (демографического, экономического и социо-культурного назначения), формы организации в обществе частной жизни лиц, совместно проживающих и хозяйствующих.

Домохозяйства выполняют свои функциональные роли (демографические, экономические, социально-психологические) в создании и потреблении благ на этапах воспроизводства домохозяйственной организации и ее участников. Само производство благ при этом может иметь два направления: во-первых, для целей обмена на рынке на другие виды благ; во-вторых, как средства существования, предназначенные для удовлетворения собственных потребностей. Во втором случае, созданные домохозяйствами средства могут иметь соответствующую стоимостную оценку (при необходимости), или не иметь ее (например, в рамках реципрокного обмена).

Исследование роли домохозяйств в сетях предполагает синтез разных теорий и подходов, включая демографические (Ф. Ле Пле, Р. Хилл и др.), социальные (Ф. Теннис, М. Маринова и др.), институциональные (Р. Поллак, Л. Тевено, Л. Болтански и др.). В экономической социологии получил развитие сетевой подход на основе трудов М. Грановеттера, Х. Уайта и др. Однако исследований роли домохозяйств в создании и функционировании неформальных экономических сетей в России, в том числе в сфере услуг, не проводилось. Исходный методологический принцип анализа экономической роли домохозяйств как полноценного агрегированного хозяйствующего субъекта сети связан с условиями существования, экономическими интересами, собственностью, системой отношений между участниками по поводу создания, распределения и присвоения результатов хозяйственной деятельности.

В России около 53 млн. домохозяйств, в которых проживает почти 143 млн. человек (среднее число участников в домохозяйстве $-2,7$ чел.). Поведение домохозяйств носит разнообразный характер, однако, имеет ряд общих признаков: координацию действий между членами, добровольность участия, наличие обязанностей и их распределение и т.д.

Основные элементы домохозяйств, способ- ствующие их участию в неформальных экономических сетях отражены на рис. 1.

Домохозяйства образуют сети как между собой, так и с другими хозяйствующими субъектами, в том числе в сфере услуг: организациями, предприятиями в виде образовательных и медицинских заведений, учреждений отдыха и развлечений, мест работы и т.п. Так, например, хороший репетитор (работник вуза) или врач могут быть элементами неформального информационного обмена, формируя, одновременно, узлы сети, создавая устойчивые связи между домохозяйствами и юридическими лицами. Подобная сеть имеет «официально-неформальное» содержание, в связи с тем, что часть благ, информации и действий в ней доступна для официального учета и формального обмена, а другая часть - не формализована, что означает тесноту отношений или родство, отсутствие правил, добровольность обязательств, отказ от открытого денежного обмена.

Виды сетей, в которых участвуют домохозяйства, разнообразны: некоммерческие и коммерческие, социальные, реципрокные, выживания, взаимопомощи и развития, по видам деятельности и др. (рис. 2).

Социальный характер таких сетей достаточно условен, ведь в них создаются, продвигаются и обмениваются блага, которые можно оценить с экономической точки зрения.

Факторы участия домохозяйств в неформальном секторе экономики разнообразны. Так, одним из них является все еще относительно низкий уровень оплаты, находящийся на грани с величиной прожиточного минимума (10,5 тыс. руб. в 2017 г.).

Еще одним фактором можно считать манипуляции с занятостью, при которой работника вынуждают перейти на пониженную оплату труда, например, в бюджетной сфере - на 0,75 или на 0,5 ставки. Для поддержания своего уровня жизни такой сотрудник вынужден осуществлять дополнительную работу, как правило, неформальную деятельность, ведь его трудовая книжка остается по месту основной занятости. В 20152016 гг. число таких случаев также возросло, составив 25\% от числа опрошенных (в 2013 г.-9\%).

В России к числу основных причин ухода «официальных» работников в теневой сектор, следует отнести увольнения, скрытую безработицу, нехватку рабочих мест, низкий уровень оплаты труда. Неблагоприятные условия осу- 


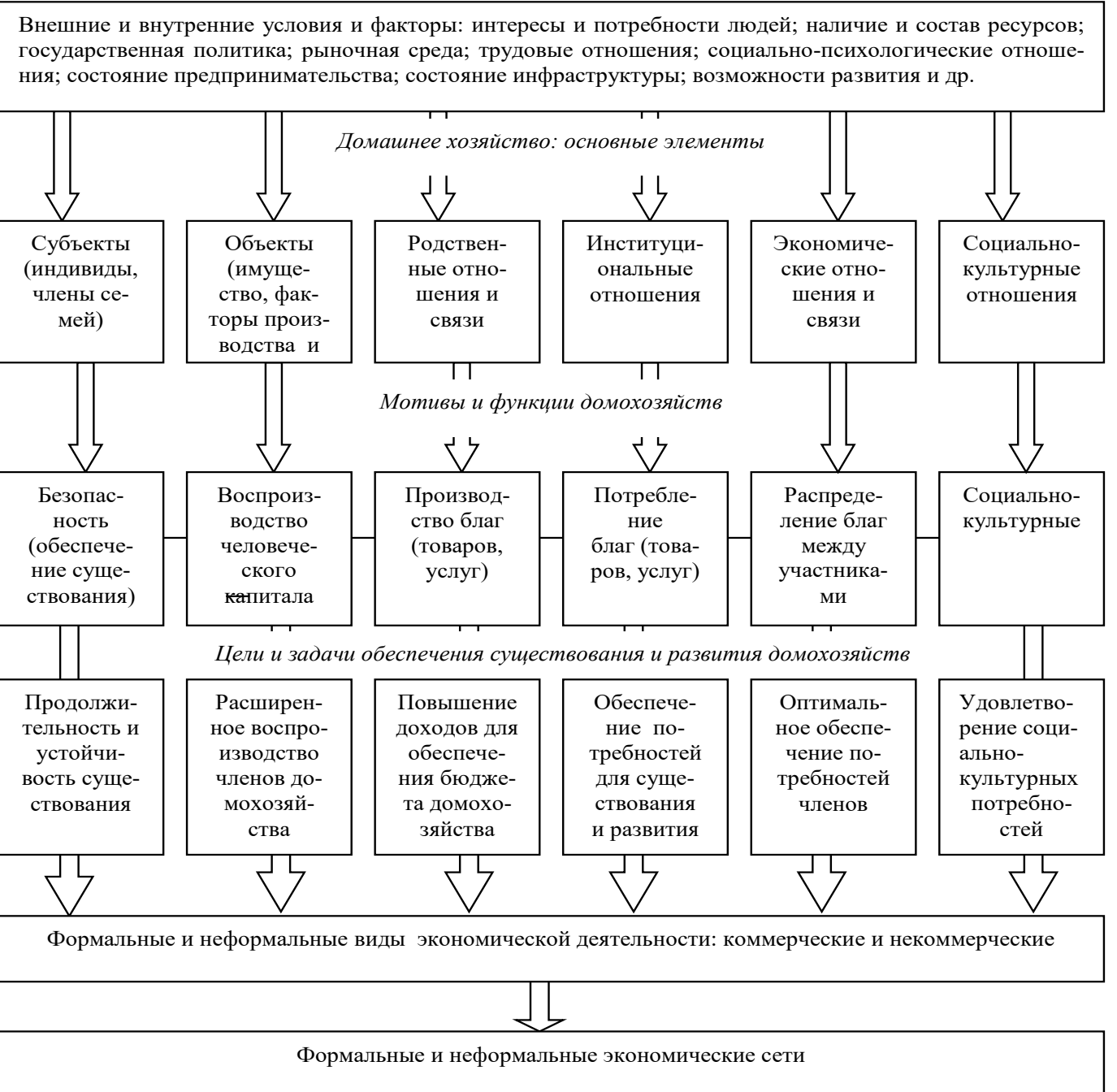

Puc. 1. Основные элементы домохозяйств

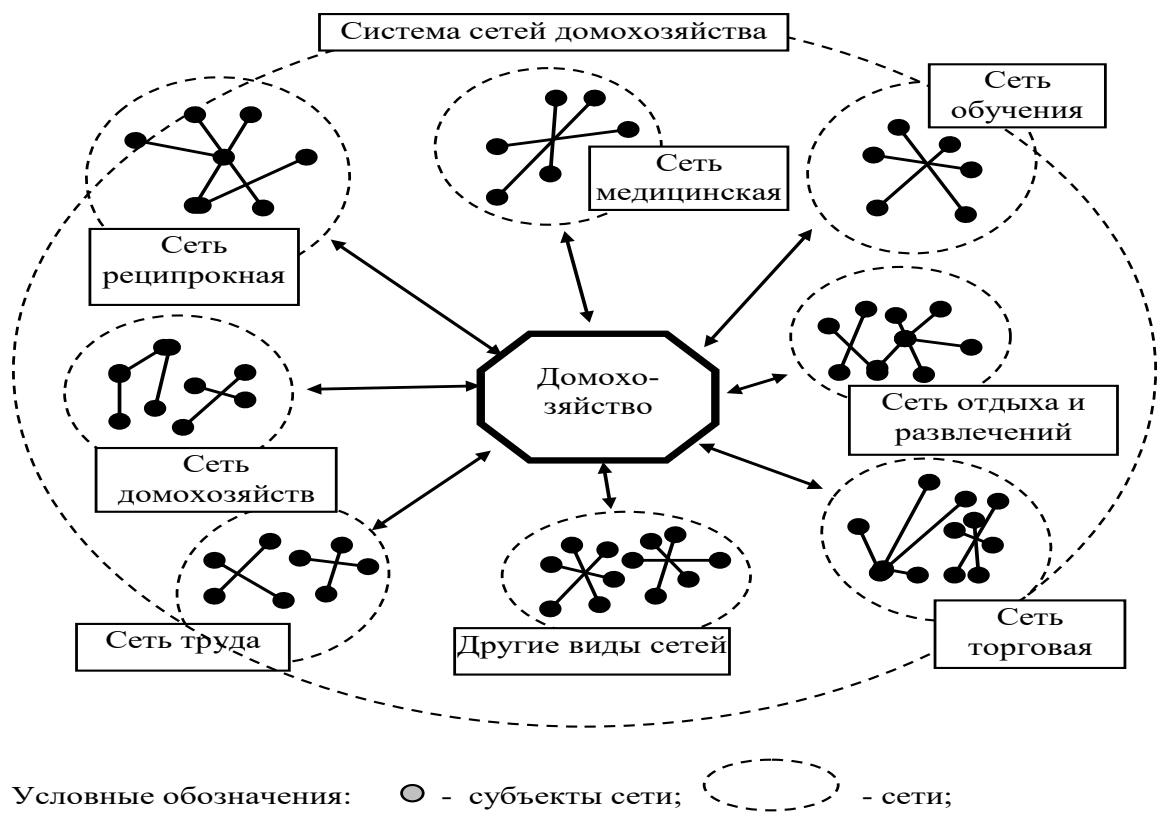

Puc. 2. Виды сетей домохозяйства 
ществления бизнеса и поддержки функционирования предприятий (исключая крупные корпорации и участников государственных проектов) вынуждают работодателей максимально экономить на всем, в том числе на издержках по зарплате.

Динамика потребления домохозяйств в РФ за последние годы имеет общий тренд к снижению [13], что свидетельствует не только о проблемах в экономике страны, но и о возможном перспективном росте участия домохозяйств в неформальном секторе экономики.

Экономические сети на принципах реципрокности. К. Поланьи отмечал три принципа осуществления деятельности: в виде домашнего хозяйства, перераспределения (редистрибуции) и реципрокности, доминировавшие на этапах неразвитого рынка [14].

Сущность домашнего хозяйства проявляется в деятельности людей по обеспечению своей нормальной жизни (воспроизведение членов семьи, развитие человеческого капитала, решение социальных проблем, удовлетворение потребностей и т.п.). Домашнее хозяйство выполняет множество функций, многие из которых не ориентированы на получение прибыли, что в определенной степени выводит его за рамки рыночного конкурентного механизма. Вместе с тем, домашнее хозяйство тесно задействовано в процессах перераспределения разнообразных благ и реципрокного обмена.

Особенность перераспределения проявляется нетоварном продуктообмене, изъятии благ, в процессах концентрации ресурсов (материальных, финансовых и др.) в едином центре и последующим их распределением между потребителями в соответствии с заданными критериями.

Понятие реципрокности (reciprocity) применяется в различных науках (медицине, психологии, социологии). В современной экономике однозначность понимания термина «реципрокность» еще не сложилась. В терминологии ряда авторов (К. Поланьи, М. Саллинз, С.Ю. Барсуковой и др.) реципрокность раскрывается как взаимность, предполагающая передачу благ в дар на нерыночной основе и взаимности с соблюдением установленного порядка. Дарообмен регулируется социальными нормами, становясь основным распределительным механизмом в данном сообществе. Концептуальный подход к реципрокности во многом был связан с необходимостью решения противоречий рыночной системы, в которой максимизация прибыли и необходимость ее эффективного функционирования во многом отрицала социально-культурные нерыночные факторы в виде доверия, честности, ответственности, взаимопомощи и т.д. Критически относясь к саморегулируемому рынку К. Поланьи считал, что экономическая жизнь вторична и подчинена социальной системе. Реципрокным взаимодействиям придается принципиально иной характер по сравнению с товарным обменом: он проходит в форме некоего бескорыстного одаривания между лично знакомыми субъектами с ожиданием взаимности, преследует целью защиту близких людей от неблагоприятных условий, способствует выживанию сообща и т.п.

Исследователи домашнего хозяйства, перераспределения и реципрокности, стремясь показать их радикальное отличие от «порочного» рынка, на самом деле раскрыли многообразие и взаимообусловленность различных форм экономической деятельности. Это характерным образом проявляется через операционализацию рассмотренных выше понятий с позиций экономического подхода. Так, анализируя реципрокность в рамках сферы услуг следует отметить существенное различие в понимании ее основополагающего элемента - «дара» между социологическим и экономическим подходами. В социологии дар не рассматривается как товар и даже несколько противопоставляется ему. Его содержание «отрывается» от товарно-вещной формы и принимает во многом абстрактную форму подарка-символа, выполняющего множество функций: знака внимания, закодированного послания, конструирования репутации, материальной инвестиции и т.п. Эти функции дар приобретает в зависимости от: «.. от ситуации, обрядовой структуры, ритуальных действий, маркирующих ситуацию как «куплю-продажу» или «дарение». Вне ситуативного контекста нет ни товара, ни дара, ни дани. Подарок - это не вещь, а ситуация, вплетенная в социальные отношения, элементом которой является акт дарения» [15].

С экономической точки зрения любой дар может быть отражен в виде соответствующих показателей, сравнен и оценен. И хотя обмены дарами осуществляются между лично знакомыми, формируя сети реципрокность, они не означают наличие полного альтруизма и отсутствие определенного баланса интересов и эквивалент- 
ности благ в этом обмене (что отмечали К. Поланьи, А Щик, Ю. Эльстер и другие) [16; 17].

В ряде работ показывается различие между реципрокностью и патрон-клиентскими отношениями. Под последним понимаются отношения между субъектами с неравными статусами, находящимися на разных уровнях объединяющей их иерархической структуры (патрон и клиент, подчиняющие и подчиненные) [18; 19]. Предоставляя свою опеку, патрон получает от клиента в виде ответного действия дань (ценности, услуги), которая по своей сути имеет признаки дара, но в принудительной форме.

В экономическом смысле дар и дань следует рассматривать более конкретно, например, в виде добровольной передачи «... собственности одного лица другому без финансового возмещения» [20, с. 164]. Дар и дань (как вещь или услуга) имеют форму собственности и стоимость, проявляемые посредством определения принадлежности определенным владельцам (через права владения, пользования и распоряжения), а также их оценки (выражения в деньгах). Очевидно, исходя из невозможности понимания бестоварных обменов как экономически обезличенных, было предложен термин «психологический рубль» [21]. Использование экономических категорий позволяет определять эквивалентность дарообмена между субъектами и величину дани в патрон-клиентских отношениях, позволяя удовлетворять ожидания партнеров, избегать кризисов и возможных разрывов отношений. Кроме того, многообразие видов реципрокных обменов делает методически сложным проведение их эмпирических исследований, анализ и количественное измерение без приведения к единой сопоставительной базе, в качестве которой выступают экономические показатели цена, стоимость, трансферты, затраты, доходы.

Пример распределения средств и благ в неформальной экономической сети на принципах реципрокности в виде внутрисемейной сети представлен на рис. 3.

Неформальность в таких сетях проявляется в том, что характер отношений (экономических, финансовых, социальных) в них закрыта и не отражается в информационном пространстве в регулярной форме (статистических отчетах, аналитических материалах и т.д.).

Пример распределения средств и благ в неформальной экономической сети на принципах реципрокности - отношений между домашними хозяйствами, отражен на рис. 4.

Оба вышеприведенных примера отличаются тем, что отношения между сторонами носят преимущественно нерыночный (нетоварный) характер, не максимизируются (по прибыли), но и не являются альтруистическими; они ориентированы на взаимность, эквивалентность, а также родство или личное знакомство.

Экономический подход, используя соответствующие категории собственности, стоимости

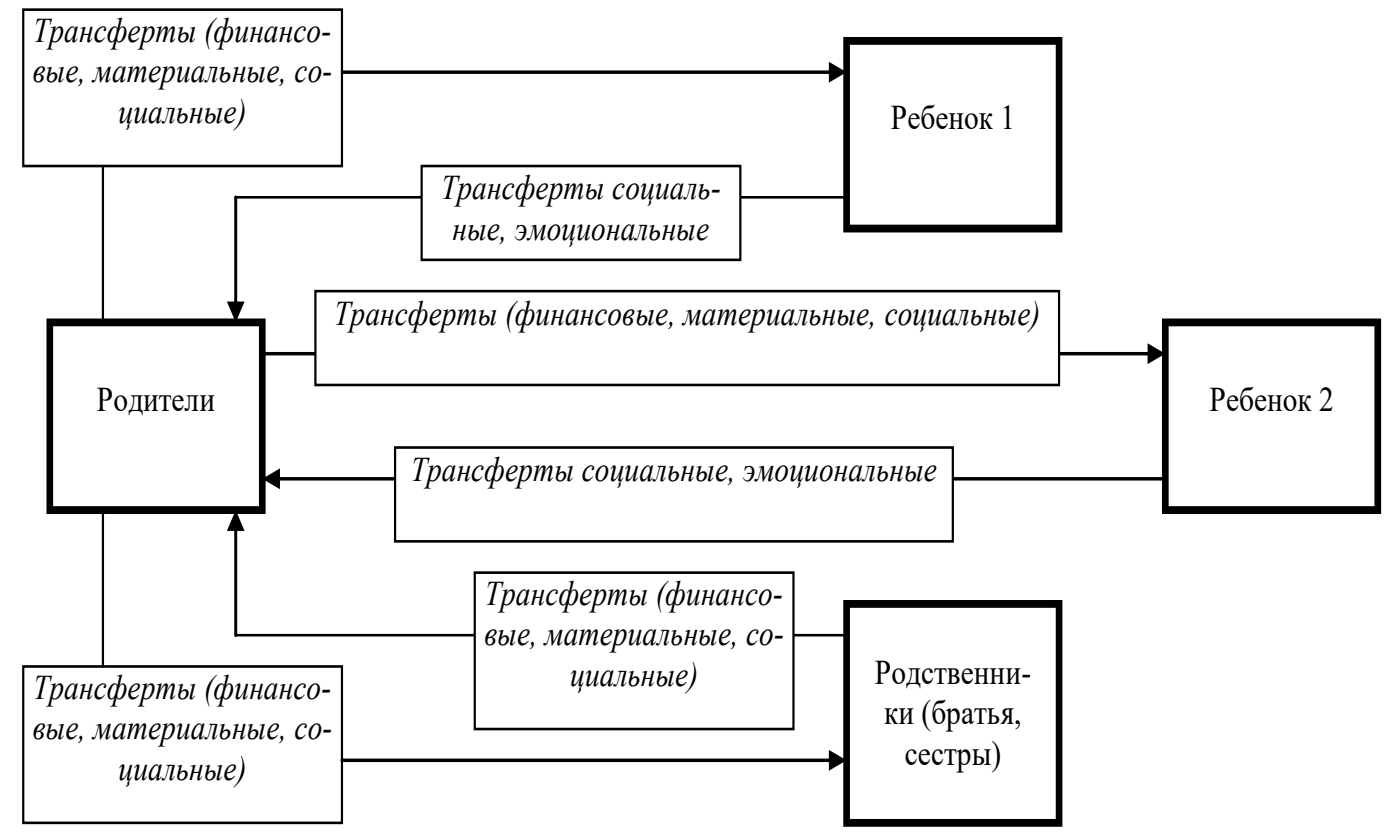

Puc. 3. Пример распределения средств и благ в неформальной экономической сети на принципах реципрокности (внутрисемейная сеть) 


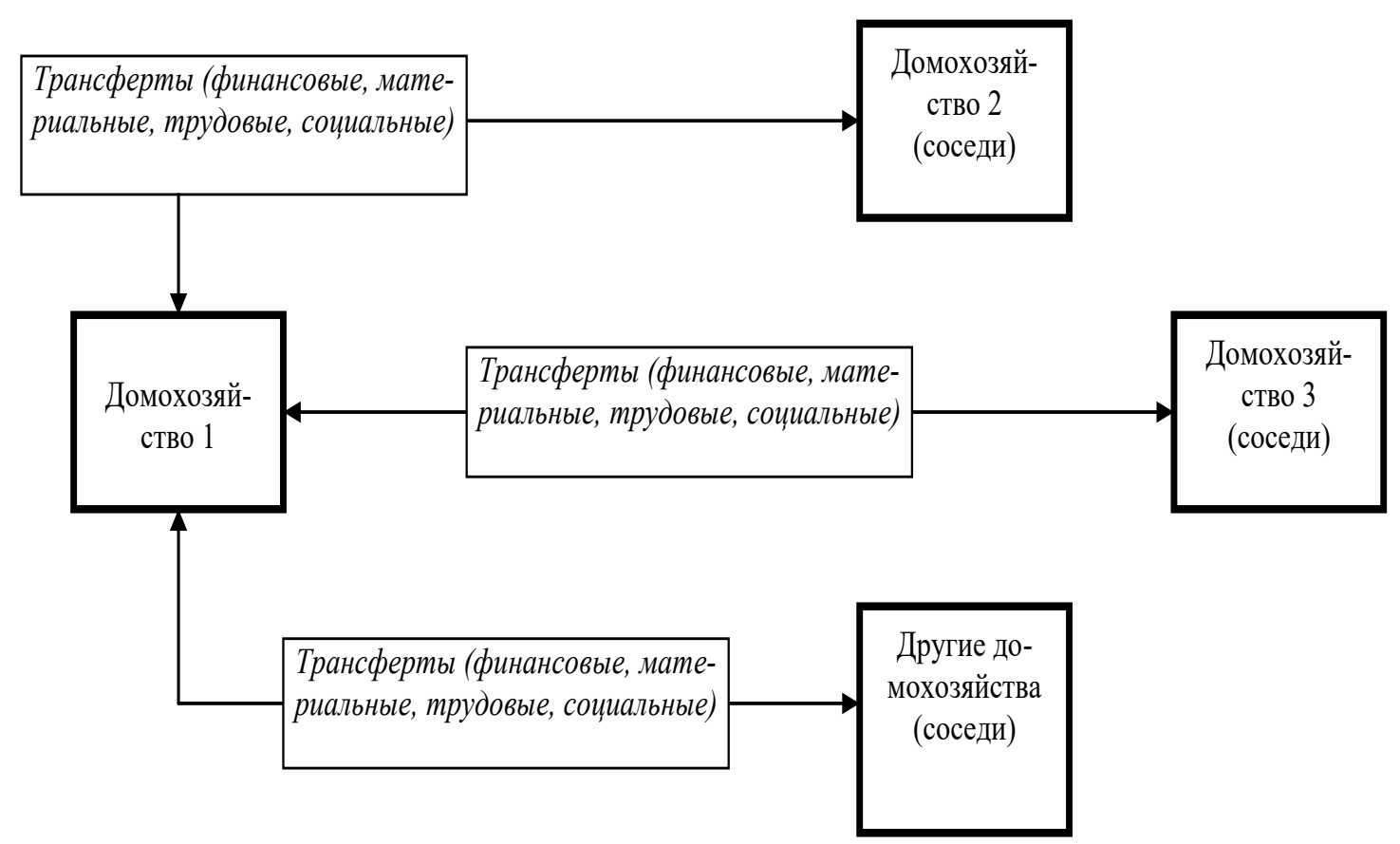

Puc. 4. Распределение средств и благ в неформальной экономической сети на принципах реципрокности - отношения между домашними хозяйствами

и т.п., дополняя их социальными отношениями, позволяет не только раскрыть весь спектр многосложности понятий домашнего хозяйства, перераспределения, реципрокности и рынка, но и показывает, что наличие границ между ними в теоретических изысканиях весьма условным. Это подтверждает и К. Поланьи, отмечая, что «... связь между формальной экономической теорией и человеческим хозяйством оказывается непрочной» [14, с. 47].

В Российской Федерации сложились системные проблемы, вызванные действующей моделью развития экономики. В условиях еще недостаточной укорененности рыночных отношений, дефицита бюджетных средств с совокупностью неблагоприятных внешнеполитических событий это ограничивает возможности перехода к новой экономике, повышение уровня ее транспарентности, создания новых дополнительных рабочих мест.

Разработка и внедрение научно обособленных механизмов сетевого взаимодействия в сфере услуг позволит опережающими темпами решить вышеуказанные проблемы.

\section{Библиографический список}

1. Ахметгареева A.А. Обеспечение конкурентоспособности предприятий сферы услуг.- Саарбрюккен: LAP LAMBERT Academic Publishing, 2017. 252 c.

2. Евстигнеев Р.Н. Современная экономика: новый концептуальный вызов // Общественные науки и современность. 2016. № 3. С.112-121.

3. Татаркин А. Перспективы неоиндустриального развития России в условиях текущих сдвигов / А. Татаркин, Е. Андреева // Экономист. 2016. № 2. С.11-22.

4. Глазьев С. Как построить новую экономику // Эксперт. 2012. № 7. С.54-57.

5. Пястолов С. Метафизика «системной модернизации» // Экономист. 2016. № 3. С.46-554.

6. Абрамовских Л. К поиску новой модели экономического развития / Л. Абрамовских, А. Бабенко // Экономист. 2016. № 10. С.34-42.

7. Авдокушин Е.Ф. Некоторые особенности функционирования предпринимательской модели «новой экономики». URL: http://www.bseu.by:8080/bitstream/edoc/3830/1/

8. Кудрявцева С. «Новая экономика»: генезис, эволюция, эффект / С. Кудрявцева // Мировая экономика и международные отношения. 2005. № 4. С. 121-125.

9. Талер Р. Новая поведенческая экономика. Почему люди нарушают правила традиционной экономики и как на этом заработать. М. Бомбора. 2017. 540 с. 
10. Altinoglu, Levent (2018). «The Origins of Aggregate Fluctuations in a Credit Network Economy», Finance and Economics Discussion Series 2018-031. Washington: Board of Governors of the Federal Reserve System. URL: https://doi.org/10.17016/FEDS.2018.031.

11. Мау В.А. Кризисы и уроки. Экономика России в эпоху турбулентности. М.: Ин-т Гайдара, 2016. 486 с.

12. Бузгалин А. В., Колганов А.И. Новая экономико-политическая реальность глобального мира: будущее России // Новая политика для новой экономики. Доклады и выступления. Под ред. А.В. Бузгалина. М.: Слово, 2003. 408 c.

13. Игнатов В. ВВП: домохозяйства лидируют в сокращении расходов, правительство - доходов. URL: http:// iforex.su/27244-VVP-domohozyaiystva-lidiruyut-v-sokrashenii-rashodov-pravitel-stvo-dohodov.html.

14. Поланьи К. Великая трансформация: политические и экономические истоки нашего времени / Пер. с англ. А. Васильева, С. Федорова, А. Шурбелева. СПб.: Алетейя. 2014. 313 с.

15. Барсукова С.Ю. Нерыночные обмены между российскими домохозяйствами: теория и практика реципрокности. Препринт WP4/2004/02. М.: ГУ ВШЭ, 2004. 52 с.

16. Sik E. «Small Is Useful» or the Reciprocal Exchange of Labour // Labour Market and Second Economy in Hungary. P. Galasi, G. Sziraczki (eds.). Frankfurt/Main; New York: Campus Verlag, 1985. 184p.

17. Эльстер Ю. Социальные нормы и экономическая теория //THESIS. 1993, т. 1, вып. 3. С.73-91.

18. Giddens A. Central problems in social theory: Action, structure and contradiction in social analysis. L.: Macmillan. $1988.53 \mathrm{p}$.

19. Ковалев Е.М. Взаимосвязи типа «патрон-клиент» в российской экономике. / Неформальная экономика. Россия и мир/ Под. Ред. Т. Шанина. М.: Логос,1999. 128 с.

20. Большой экономический словарь/Под ред. А.Н. Азрилияна.- М.: Институт новой экономики, 1999.1248 с.

21. Штейнберг И.Е. Реальная практика стратегий выживания сельской семьи - «сетевые ресурсы» // Куда идет Россия?.. Формальные институты и реальные практики / Под общ. ред. Т.И. Заславской. М.: МВШСЭН, 2002. 183 c. 